\title{
Reflexões sobre Gestão Escolar à partir da Percepção de Gestores da Rede Municipal
}

\author{
Alzineide dos Santos Galdino ${ }^{1}$; Jucinei dos Santos Martins ${ }^{l}$; Jurandi José Celestino ${ }^{l}$;
} Washington Silva Rufino ${ }^{I}$; Luzia Coelho Rodrigues ${ }^{2}$

\begin{abstract}
Resumo: Este artigo situa a gestão escolar, com o objetivo de descrever, a partir da percepção do gestor, o ambiente escolar, seus elementos, e a prática de gestão, adotando, para tanto, o referencial sobre as prerrogativas do gestor escolar no contexto da gestão democrática. A pesquisa é de natureza descritiva e exploratória, desenvolvida a partir de entrevista com gestores da rede municipal de ensino. As informações foram analisadas qualitativamente. Os resultados apontam a existência de participação democrática na gestão escolar nas instituições pesquisadas. No que concerne a competências requeridas para o gestor, infere-se, a partir da percepção dos participantes, que há necessidade de incentivar ações específicas de capacitação, principalmente no que se refere à dimensão financeira de gestão.
\end{abstract}

Palavras-chave: Gestão escolar, Descentralização, Competências, percepção de usuários.

\section{Reflections on School Management from the Perception of Municipal Network Managers}

\begin{abstract}
This article placed on the school management, in order to describe, from the perception of the manager, the school environment, its elements and of management practice, adopting, for this purpose, the reference about the prerogatives of the school manager in the context of Management democracy. The research of descriptive and exploratory nature, developed from an interview with managers of the municipal education network. The information was analyzed qualitatively. The results point the existence of democratic participation in the school management in the researched institutions. With regard to the necessary skills for the manager, it is inferred from the participants' perception that there is a need for incentives in specific training actions.
\end{abstract}

Key words: School management, Decentralization, Skills, perception of users.

\section{Introdução}

As escolas são administradas por gestores escolares que devem ter responsabilidade e motivação para desenvolver suas tarefas no âmbito escolar. Dessa forma, o líder estabelece o ritmo das atividades escolares, criando um clima para a aprendizagem. Suas ações devem contribuir para o nível de profissionalismo dos professores e atitude dos alunos, e sua motivação e empenho dão credibilidade junto à comunidade, de forma que seja possível

\footnotetext{
${ }^{1}$ Bacharelado em Administração Pública, em andamento, na Universidade Federal do Vale do São Francisco (Univasf). Contatos: alzineide.dossantos@gmail.com,jucinei.martins@gmail.com,jurandir_cdc@hotmail.com,wsilr@hotmail.com.

${ }^{2}$ Mestra em Administração (UFBA). Licenciatura em Letras (UPE), especialista em Capacitação Pedagógica de Professores (UFRPE). Docente do Bacharelado em Administração Pública da SEaD/Univasf. Contato: luzia.coelho.08@gmail.com 
contribuir para a criação de espaços de diálogo e para a construção do trabalho colaborativo, influenciando a qualidade do ensino (SOUZA; MARTHINS; CARVALHO, 2017).

Sendo assim, o gestor escolar tende a administrar os recursos financeiros e a organização do seu corpo técnico e docente (professores, coordenadores e quadro administrativo), objetivando atender ao seu público (alunos e pais) de forma eficiente e eficaz, com educação de qualidade, atendendo aos anseios da comunidade. A discussão não é recente. Desde o fórum realizado em Buenos Aires, na Argentina, em 1998, pelo Instituto Internacional de Planejamento da Educação (IIPE), da UNESCO, foi discutido o tema da formação de recursos humanos para a gestão educacional, entendendo que a gestão educativa deverá dar prioridade a ações transformadoras, adotando diferentes técnicas e ferramentas voltadas à gestão educacional, sendo dotada de agilidade e flexibilidade, a fim de enriquecer os processos de tomada de decisões e buscar atender com sucesso as necessidades de uma sociedade moderna.

Nessa perspectiva, pretende-se contextualizar, neste estudo, a Gestão nas escolas da rede municipal de ensino. O objetivo é descrever, a partir da percepção do gestor, o ambiente escolar, seus elementos, e a prática de gestão, adotando, para tanto, o referencial sobre as prerrogativas do gestor escolar no contexto da gestão democrática.

\section{Competências do Gestor Escolar: Gestão de Pessoas.}

O gestor escolar precisa articular-se com todos os setores da Instituição, avaliando, sempre, o desempenho das ações em todos os âmbitos, com o objetivo de lograr êxito na implementação de suas ações, uma vez que o papel por ele assumido pode impactar a aprendizagem e o ambiente educacional (ABRUCIO, 2010). Sendo assim, a gestão participativa descentraliza o poder e busca, incessantemente, por meio de recursos humanos, a inserção de mentalidades idealizadoras e a aplicabilidade de inovações no trabalho do dia-dia, em cada setor, priorizando o diálogo e a participação social na elaboração e execução do projeto pedagógico e na criação de um espaço educacional autônomo (LUCK, 2009). 
Acrescenta-se, ainda, que a gestão envolve tanto aspectos gerenciais quanto técnicos para o alcance dos objetivos institucionais, isso tanto no que se refere à dimensão pedagógica (essência da escola) quanto à administrativa (LIBÂNEO; OLIVEIRA; TOSCHI, 2012). De acordo com Ribeiro (2008), a gestão democrática estabelece igualdade entre as pessoas e representa a garantia de direitos dentro da instituição escolar, permitindo o planejamento coletivo e a distribuição de responsabilidades e/ou competências. Para a autora, a participação dos colaboradores nos processos de gestão contribui para aumentar a motivação e, consequentemente, melhorar o desempenho individual e institucional.

Os recursos humanos são imprescindíveis na constituição da organização da gestão de pessoas, na importância e vitalidade do conjunto de ações que compreende a gestão e suas peculiaridades, no relacionamento e comportamento que norteiam e predominam seus conceitos no âmbito de um corpo de profissionais, mesmo que com diferentes prerrogativas. Sendo assim, a formação de gestores na área educacional vem sendo temas constantes de pesquisas (NETO, 2017), demonstrando que a gestão pública busca a flexibilização dos processos no sentido de melhorar a qualidade dos serviços prestados.

Nesse novo cenário, o capital intelectual é o diferencial competitivo (PRADO; SILVA; SILVEIRA, 2012), o que implica a necessidade de priorizar ações que promovam o desenvolvimento mútuo de competências (gestor, colaboradores) e, com isso, agregar valor à instituição escolar (DUTRA, 2011), sendo necessário, para tanto, identificar as competências requeridas, para o gestor, em todas as dimensões: administrativas, pedagógicas, sociais e políticas da organização (PRADO; SILVA; SILVEIRA, 2012), a fim de permitir a gestão de pessoas, de atividades educacionais e de recursos materiais e financeiros, além de articular atividades de fiscalização e de avaliação das ações, de acordo com as diretrizes educacionais.

\section{Competências do Gestor Escolar: Gestão Financeira (Planejar, Executar e Prestar Contas)}

A gestão financeira nas unidades escolares municipais seguem três princípios básicos: Planejamento, Execução e Prestação de contas. Os recursos financeiros da educação municipal foram descentralizados no final de 2009 para início de 2010, quando passaram a ser 
regido pelo Regimento Unificado das Escolas da Rede Municipal de Educação, amparado pela Lei de Diretrizes e Bases da Educação Nacional (LDB), o qual estabelece as Diretrizes Técnico-Pedagógicas, Administrativas e Disciplinares das Unidades Escolares integrantes do Sistema Municipal de Ensino, criado e mantido pelo Poder Público Municipal.

Desde então, os gestores passaram a administrar 100\% dos recursos disponibilizados pelos seguintes programas: Fundação Nacional de Desenvolvimento da Educação (FNDE), Programa Dinheiro Direto na Escola (PDDE), Programa de Autonomia Financeira na Escola (PROAFE). Esse capital é depositado na conta bancária da entidade executora (UEx), entidade de direito privado, sem fins lucrativos, representativo da comunidade escolar. Esses recursos são destinados exclusivamente para suprir necessidades básicas, gastos com aquisição de material permanente (Capital) e com material de consumo, manutenção e serviços (Custeio).

Portanto, para utilização dos recursos públicos, os gestores precisam ter conhecimentos específicos sobre: a Lei de Responsabilidade Fiscal (trata da responsabilidade dos agentes quanto à utilização de recursos públicos), a Lei de Direito Financeiro (trata dos orçamentos públicos), a Lei de Licitações (trata dos procedimentos relacionados às compras feitas pela administração), como também, seguir as orientações do Tribunal de Contas, a respeito dos procedimentos legais.

A prestação de contas segue as normas e os critérios estabelecidos pelo município e tribunal de contas. Para tanto, o gestor precisa está fundamentado e documentado através de notas fiscais, relatórios, e documentação apropriada, nos termos dos formulários fornecidos pela secretaria de educação. Essa prestação precisa ser aprovada pela unidade executora (Conselho de pais e mestres), lembrando que o conselho de pais e mestres, além de acompanhar e avaliar a qualidade dos serviços prestados, deve também participar da preparação do Projeto Pedagógico da escola (LIBÂNEO; OLIVEIRA; TOSCHI, 2012).

O Conselho escolar, nesse sentido, deve atuar como "instância de discussão, acompanhamento e deliberação, na qual se busca incentivar uma cultura democrática, substituindo a cultura patrimonialista pela cultura participativa e cidadã" (MEC, 2004, p.35), representando espaço de discussão e negociação para os encaminhamentos das demandas educacionais, permitindo a participação social e promovendo a gestão democrática. 


\title{
Limitações, Potêncialidade e Capacitação do Gestor Escolar.
}

A escola tem como função social a construção e a socialização de conhecimentos (OLIVEIRA, 2013), o que requer do gestor a habilidade de buscar o fortalecimento externo, envolvendo a comunidade na preparação, no acompanhamento e na avaliação dos serviços prestados, principalmente, viabilizando a participação dos pais (PARO, 2012; LIBÂNEO; OLIVEIRA; TOSCHI, 2012) para cumprir essa função, construindo novos saberes, e praticar o exercício da cidadania (GANZELLI, 2011).

Nesse contexto, a figura principal do líder dentro do ambiente educacional, no que tange a comunidade escolar, é atuar como principal responsável na condução de medidas, tais como: coordenar e mobilizar todo o processo na escola, compartilhando todo aprendizado, tendo como foco a competência na qualidade e conjuntura do processo educativo no todo. De acordo com Philippe Perrenoud (2000, p.103), administrar recursos de uma escola significa:

\begin{abstract}
fazer escolhas, ou seja, é tomar decisões coletivamente. Na ausência de projeto comum, uma coletividade utiliza os recursos que tem, esforçando-se, sobretudo, para preservar certa equidade na repartição dos recursos. Por essa razão, se não for posta a serviço de um projeto que proponha prioridades, a administração descentralizada dos recursos pode, sem benefício visível, criar tensões difíceis de vivenciar, com sentimentos de arbitrariedade ou de injustiça pouco propícios à cooperação.
\end{abstract}

Nesse contexto, cabe ao gestor buscar meios para ampliar a participação de todos os segmentos na tomada de decisão, exigindo esforço humano (PARO, 2012) para a condução do processo de gestão eficiente, derivada da participação da comunidade escolar, mediante ações e intervenções abrangendo todos os setores estruturais do espaço físico e pedagógico, que permitem as adequações pertinentes para o bom desempenho das atividades do corpo docente e discente. Sendo assim, é importante destacar a cultura organizacional, considerar a subjetividade das práticas culturais, adotando a concepção democrático-participativa de gestão (LIBÂNEO; OLIVEIRA; TOSCHI, 2012) na relação entre gestor e comunidade escolar para o alcance dos objetivos individuais e institucionais (LÜCK, 2000; FERNANDES, 2016; SOUZA; MARTHINS; CARVALHO, 2017). 
Para esse envolvimento com a comunidade escolar, o gestor precisa desenvolver competências técnicas, políticas e pedagógicas, com habilidades básicas organizacionais e de comunicação, além das características individuais, a exemplo de liderança, negociação, articulação pedagógica (PRADO; PRADO, 2001), o que, requer atenção para que o gestor não dedique tanto tempo a questões administrativas (atividade meio) em detrimento das ações pedagógicas, atividade fim (GADOTTI, 2004). Ou seja, o gestor precisa desenvolver competências: administrativa, financeira, política, pedagógica, além de observar a legislação pertinente.

\section{Metodologia}

A partir da revisão de literatura e com base no referencial sobre gestão escolar, realizou-se a pesquisa de campo em 10 unidades escolares do município de Juazeiro-BA, correspondendo a $10 \%$ do universo de escolas do município. A escolha das unidades deu-se por sorteio. As informações foram coletadas no período de janeiro a maio de 2017, por meio de entrevista com gestores. O roteiro de entrevista foi preparado com questões abordando os seguintes aspectos: critérios para o exercício do cargo de gestor, formas de escolha, formação de equipe, descentralização de recursos, treinamentos para aplicação de recursos, participação de órgãos colegiados nas deliberações, fiscalização e importância da gestão escolar.

A pesquisa é descritiva e exploratória, pois visou identificar a percepção do gestor sobre a prática de gestão no ambiente escolar. Sabe-se que a temática não é nova, mas o intuito foi familiarizar-se (GIL, 2008), a partir da visão do gestor, com a prática de gestão no contexto da gestão participativa, por meio de entrevista in loco. Conforme Richardson (1999, p. 160), a entrevista é "uma técnica importante que permite o desenvolvimento de uma estreita relação entre as pessoas. É um modo de comunicação no qual determinada informação é transmitida".

Em observância aos aspectos éticos de pesquisa, os participantes assinaram o termo de consentimento livre e esclarecido. 
As informações coletadas foram analisadas seguindo a Análise de Conteúdo (BARDIN, 2006), em categorias temáticas preestabelecidas: Gestão de Pessoas e Gestão de Recursos. Sendo assim, a abordagem da pesquisa é predominantemente qualitativa, tendo como base o processo de entendimento das informações coletadas.

\section{Resultados}

A partir de análise dos dados estatísticos da Secretaria de Educação do Município de Juazeiro-BA, constatou-se a existência de 132 escolas, das quais 32 são creches. 34 escolas possuem ensino fundamental do $1^{\circ}$ ao $9^{\circ}$ ano, e as demais ofertam do $1^{\circ}$ ao $5^{\circ}$ ano. Das 100 escolas de ensino fundamental, foram sorteadas 10 para a pesquisa de dados primários. As unidades escolares são assim caracterizadas:

a) Infraestrutura: todas são estruturadas com biblioteca, sala de professores, salas climatizadas, espaço próprio para refeitório e quadra esportiva.

b) Corpo de gestores: as 10 unidades pesquisadas são administradas por pessoas do gênero feminino, todas com formação de nível superior, sendo que a maioria possui especialização.

c) Nível de ensino: As escolas ofertam o Ensino Fundamental (escolas da rede pública: Educação Básica).

d) Forma de ingresso do gestor: eleito por pais, alunos e servidores (democraticamente).

e) Duração do mandato do gestor: quatro anos;

As falas dos gestores foram distribuídas em categorias e agrupadas dentro das temáticas: Gestão de Pessoas e Gestão de Recursos, conforme dados a seguir: 


\section{Percepção de gestores sobre a prática da Gestão de Pessoas}

De acordo com os entrevistados a gestão escolar é importante para conduzir e liderar os trabalhos junto à comunidade, promover e organizar o processo de ensino-aprendizagem:

É importante para a liderança e organização do pedagógico e administrativo (GESTOR 1). [...] organiza todo espaço e processo de ensino-aprendizagem, gerindo esforços individuais e coletivos para melhoria do ensino (GESTOR 4). É a base da Escola. Deve ser reconhecida como elemento determinante para o desenvolvimento do processo educativo (GESTOR 2).

Convergindo para o empreendimento de esforço humano para possibilitar a participação nas decisões (PARO, 2012; LÜCK, 2000; FERNANDES, 2016; SOUZA; MARTHINS; CARVALHO, 2017), a importância da gestão escolar, a partir dos entrevistados, caminha para "promover o desenvolvimento intelectual de uma sociedade" (GESTOR 7), liderando "um grupo, onde as nuances de uma gestão perpassa por resolver conflitos e gerir recursos" (GESTOR 3), acreditando que as competências serão definidas de acordo com a "linha de trabalho definida com autonomia para traçar e trilhar seu próprio caminho em consonância com as diretrizes da Secretaria de Educação" (GESTOR 5).

Para implementar as ações, a escolha do gestor é realizada por meio de eleição direta na comunidade escolar (pais, alunos e servidores) e certificação, com tempo de gestão de 4 a 8 anos, uma vez que é permitida a reeleição. Em relação às competências requeridas (PRADO; SILVA; SILVEIRA, 2012), a maioria dos entrevistados respondeu que é preciso ter formação em Gestão Escolar, competência não exigida no ato do exercício da função, pois o critério é ser professor efetivo da rede.

Nesse sentido, apenas metade dos entrevistados (50\%) entende que o processo de certificação e a formação continuada são suficientes para desenvolver as competências requeridas aos gestores, os quais buscam, bimestralmente, orientação junto ao setor de prestação de contas da Secretaria de Educação, a exemplos dos relatos: "Não, porém se faz necessário para o processo de construção de um bom gestor" (GESTOR 3); "não, mas dá base para desenvolver melhor o trabalho" (GESTOR 5); "ajuda ao gestor, mas alguns aspectos como experiência, calma....(GESTOR 4), acrescentando que participam de formações periódicas e de encontros com a equipe administrativa sempre que necessário. 
Ainda sobre a certificação e a formação continuada, um dos entrevistados afirmou que não são suficientes, pois "a experiência vivenciada no transcorrer da gestão são desafios constantes, tanto na dimensão financeira quanto na pedagógica e administrativa" (GESTOR ). Depreende-se, das falas dos entrevistados, que é preciso ter uma experiência em gestão, mas que a formação em Gestão Escolar contribui para o bom desempenho do gestor.

Quanto à participação da comunidade nas decisões, todos os entrevistados responderam que o Conselho Escolar é convocado para analisar e aprovar os recursos aplicados, e que são realizadas cotações e tomadas de preços para a realização de compras da Unidade Escolar.

\begin{tabular}{|l|l|}
\hline Gestor 4 & $\begin{array}{l}\text { O conselho escolar é convocado para definir as prioridades e para a prestação de } \\
\text { contas. Com isso, os membros têm a função de fiscalizar e de deliberar todos os } \\
\text { recursos da Unidade Executora (UEX). }\end{array}$ \\
\hline Gestor 5 & Sim, porém, com muita dificuldade para reunir o conselho. \\
\hline Gestor 1 & Sim, bimestralmente. \\
\hline Gestor 7 & Sempre. \\
\hline
\end{tabular}

A autonomia, outra característica da gestão democrático-participativa (GANZELLI, 2011), surgiu nos relatos de apenas parte dos entrevistados, pois 50\% dos gestores consideram essa autonomia como relativa, uma vez há necessidade de aprovação das ações pelo Conselho. Infere-se, a partir dos relatos, que há certa confusão de interpretação em relação ao conceito de gestão participativa.

\section{Gestão Financeira}

De acordo com participantes, os repasses financeiros são feitos através da Fundação Nacional de Desenvolvimento da Educação (FNDE) com o programa Dinheiro Direto na Escola (PDDE); federal, e do Programa de Autonomia Financeira na Escola (PROAFE), da esfera municipal. 
O repasse financeiro é feito através de programas federais e municipais. Temos PROAPE (Programa de autonomia Financeira na Escola) como recurso municipal; PDDE (Programa Dinheiro Direto na Escola) e Mais Educação que são os recursos federais. Esses recursos são depositados no Caixa Escolar, com vistas ao desenvolvimento de ações para melhoria do processo de ensino-aprendizagem. Essas ações são deliberadas em assembleia com o Conselho Escolar (GESTOR 2).

Todos os entrevistados relataram a existência de uma conta para o repasse dos recursos financeiros a serem executados em parceria com o Conselho Escolar ou associação de pais e mestres. Ou seja, a descentralização é de $100 \%$.

No que tange à gestão desses recursos, os gestores recebem capacitação/treinamento para a utilização dos recursos financeiros, por parte da Secretaria de Educação. Percebe-se, a partir dos relatos dos entrevistados, que não existe comissão de licitação. Porém, alguns desses gestores consideram que os Conselhos escolares e a Associação de pais e mestres funcionam como comissão de licitação, o que não converge com as funções dos órgãos colegiados, os quais, segundo o MEC, "têm como atribuição deliberar sobre questões politicopedagógicas, administrativas, financeiras, no âmbito da escola", devendo, para tanto, ter funções deliberativa, consultiva, fiscal e articuladora.

Sobre e existência de capacitação para utilização dos recursos financeiros, a maioria dos participantes afirmou ter participado de treinamento oferecido pela Secretaria de Educação. No que tange à execução desses recursos, todos os entrevistados responderam que houve melhoria depois da descentralização da execução de políticas, informando que a fiscalização é feia pelos membros do Conselho por meio de prestação de contas: "através da Associação de Pais e Professores (APP)" (GESTORES 5 e 7); "através da APP e do Conselho Fiscal (Gestor 3); "na formação da associação existe um grupo que faz o trabalho, a própria Seduc e o Conselho Fiscal” (GESTOR 1). Os demais participantes informaram que realizam prestação de contas ao Conselho Escolar, aos pais e responsáveis, ao setor financeiro e à Secretaria de Educação com envio ao FNDE.

Sobre os conhecimentos da legislação educacional, os participantes avaliam que observam as diretrizes advindas do Ministério da Educação e de outros mantenedores, a exemplo de metas estabelecidas pelos Programas de Governo, os prazos para prestação de contas, utilização de recursos direcionados ao ensino-aprendizagem, bem como as orientações do Fundo Nacional de Desenvolvimento da Educação (FNDE). Nesse sentido, a manutenção 
do prédio Escolar, tais como pequenos reparos e retoques são realizados feitos com recursos da Escola (PROAFE). Já as reformas gerais são feitas através da Secretaria de Educação.

\section{Percepção dos Gestores sobre a Descentralização de Recursos}

Sobre as vantagens da descentralização de recursos, os entrevistados apontaram a autonomia da escola em gerenciar e resolver problemas, a possibilidade de deliberação em plenária, o envolvimento da comunidade nas deliberações, a possibilidade de utilizar recursos em questões prioritárias e a agilidade na execução das ações.

Em relação às desvantagens, os participantes relatam que há dificuldades para reunir os órgãos colegiados, para formar o Conselho Escolar e, consequentemente, deliberar coletivamente. Relatam, ainda, que os recursos financeiros liberados não são suficientes para atender as necessidades institucionais.

\section{Considerações Finais}

Tendo em vista que o objetivo deste projeto foi analisar a prática administrativa do Gestor Escolar e suas implicações em relação ao cumprimento das metas educacionais, percebe-se que, nas unidades pesquisadas, o gestor atua como multiplicador de competências em gestão de recursos financeiros, além de procurar proporcionar um ensino de qualidade com transparência e compromisso. Também foi percebido, a partir dos relatos, que há a participação da comunidade e do Conselho Escolar, como forma de gerir os recursos recebidos pelo governo, evidenciando a existência de práticas de gestão democráticoparticipativa.

No entanto, há divergência entre os participantes no que concerne à autonomia do gestor, sugestivos da não aceitação da inserção da comunidade na aplicação dos recursos financeiros da escola, bem como evidenciando a necessidade de ações específicas de capacitação, inclusive para a dimensão gestão financeira. 
A descentralização de recursos (mesmo que insuficientes para as prioridades) surgiu, nos relatos dos participantes, como ponto positivo para a execução das políticas educacionais, nas unidades pesquisadas, indicando que a gestão financeira foi entendida, pelos participantes, como competência da escola.

Sugere-se, como desdobramento do estudo, uma análise do planejamento e da aplicação de recursos financeiros em consonância com o projeto pedagógico da escola.

\section{Referências}

ABRUCCIO, Fernando Luiz. Gestão escolar e qualidade da Educação: um estudo sobre dez escolas paulistas. Estudos \& Pesquisas Educacionais - Fundação Victor Civita. São Paulo, 2010.

BARDIN, L. Análise de Conteúdo. Lisboa: Edições 70, 2006.

BRASIL. Lei no 9394, de 20 de dezembro de 1996. Lei de Diretrizes e Bases da Educação Nacional. Brasília, DF, 20 dez. 1996.

FERNANDES, P.T.B. A gestão democrática em uma escola pública: o perfil de participação dos pais e suas percepções sobre a mesma. 2016, 177 f. Dissertação (mestrado). UNESP, 2016.

DUTRA, J. S. (Org.). Gestão por competências. 2. ed. São Paulo: Gente, 2001.

GADOTTI, Moacir. Concepção dialética da educação: um estudo introdutório. São Paulo: Cortez, 2001.

GANZELI, Pedro. Reinventando a escola pública por nós mesmos. Campinas: Alínea, 2011 LIBÂNEO, J. C.; OLIVEIRA, J. F.; TOSCHI, M. S. Educação escolar: políticas, estrutura e organização. São Paulo: Cortez, 2012.

GIL, Antonio Carlos. Como elaborar projetos de pesquisa. 5. ed. São Paulo: Atlas, 2008.

LIBÂNEO, José Carlos; OLIVEIRA, João Ferreira de; TOSCHI, Mirza Seabra (Orgs.). Educação escolar: políticas, estrutura e organização. 10. ed. rev. e ampl. São Paulo: Cortez, 2012.

LÜCK, Heloísa. Perspectivas da Gestão Escolar e Implicações quanto à Formação de seus Gestores. Em Aberto, Brasília, v. 17, n. 72, p. 11-33, fev./jun. 2000.

RIBEIRO, Amélia Escotto do Amaral. Pedagogia empresarial: Atuação do pedagogo na empresa. Rio de Janeiro: Wak 2008 MEC. Secretaria de Educação Básica. Programa nacional de fortalecimento dos conselhos escolares. Brasília: MEC, SEB, v.07, 2006. 
NETO. Luiz Gonzaga da Silva. Políticas Públicas e Gestão: PROGEPE - Programa de Formação Continuada de Gestores Escolares de Pernambuco e o Desafio do desenvolvimento de Competências em Gestão. 2013, Dissertação (Mestrado em Ciências da Educação). Escola Superior de Educação Almeida Garret ,Lisboa, 2017. Disponível em: <http://recil.grupolusofona.pt/handle/10437/8023 > . Acesso em: 20 jul. 2017.

OLIVEIRA, João Ferreira de. A função social da educação e da escola pública: tensões, desafios e perspectivas. In: FERREIRA, Eliza Bartolozzi; OLIVEIRA, Dalila Andrade (Orgs.). Crise da escola e políticas educativas. 2. ed. Belo Horizonte: Autêntica, 2013. p. 237-252.

PARO, Vítor Henrique. Administração escolar: introdução crítica. 17. ed. revista e ampliada. São Paulo: Cortez, 2012.

PORTAL DA TRANSPARÊNCIA. Regimento Unificado das Escolas da Rede Municipal de Educação. Disponível em: <http://www.portaldatransparencia.com.br/prefeitura/juazeiro/?página=abreDocumento\&arquivo= 37EB015B8D46>. Acesso em 23 dez. 2016.

PRADO, Flávio Rodrigues; SILVA, Josélia Rita da; SILVEIRA, Luiz Flávio Vianna. Competências requeridas para diretores escolares: um estudo na escola estadual de ensino médio "Monsenhor Miguel de Sanctis". In: Simpósio de Excelência em Gestão e Tecnologia: IX SEGeT, 2012. Disponível em : 〈http://www.aedb.br/seget/arquivos/artigos12/46416578.pdf>. Acesso em 20 jul. 2017.

RICHARDSON, R. J. Pesquisa social: métodos e técnicas. São Paulo: Atlas, 1999.

SOUZA, Laura Tereza; MARTINS, Alcina de Oliveira; CARVALHO, Margarida Alice. Influência da liderança na qualidade da gestão democrática de uma escola pública. Revista Liberato, Novo Hamburgo, v. 18, n. 29, p. 01-132, jan./jun. 2017. Disponível em: < http://revista.liberato.com.br/ojs-2/index.php/revista/article/view/462/275>. Acesso em: 02 jul. 2017.

Como citar este artigo (Formato ABNT):

GALDINO, Alzeneide dos S.; MARTINS, Jucinei dos S.; CELESTINO, Jurandi J.; RUFINO, Wasington S.; RODRIGUES, Luzia C. Reflexões sobre Gestão Escolar à partir da Percepção de Gestores da Rede Municipal. Id on Line Revista Multidisciplinar e de Psicologia, 2017, vol.11, n.37, p. 718-730. ISSN: 1981-1179.

Recebido: 25/09/2017

Aceito: 29/09/2017 